\title{
Overexpression of DEP domain containing mTOR-interacting protein correlates with poor prognosis in differentiated thyroid carcinoma
}

\author{
LEI PEI ${ }^{1}$, PINGFANG XIE ${ }^{2}$, ENXIANG ZHOU ${ }^{2}$, QIAN YANG $^{2}$, YI LUO $^{3}$ and ZHONGHUA TANG ${ }^{2}$ \\ ${ }^{1}$ Department of General Surgery, Xiangya Hospital, Central South University, Changsha, Hunan 410008; ${ }^{2}$ Department of \\ Breast and Thyroid Surgery, Xiangya Second Hospital, Central South University, Changsha, Hunan 410011; \\ ${ }^{3}$ Department of Endocrine Oncology, Hunan Cancer Hospital, Changsha, Hunan 410013, P.R. China
}

Received May 2, 2011; Accepted May 30, 2011

DOI: $10.3892 / \mathrm{mmr} .2011 .503$

\begin{abstract}
DEP domain containing mammalian target of rapamycin (mTOR)-interacting protein (DEPTOR), a recently identified mTOR-interacting protein, is a novel candidate oncogene. Previous studies reveal that high DEPTOR expression is required to maintain $\mathrm{PI} 3 \mathrm{~K}$ and Akt activation and to inhibit apoptosis. However, its significance in differentiated thyroid carcinoma (DTC) is not yet known. The present study verifies the mRNA and protein expression of DEPTOR in five cell lines, DTC tissues and normal adjacent tissues. Tissue microarrays of 114 DTC patients were used to detect DEPTOR protein expression. The assessment of DEPTOR levels demonstrated that DEPTOR in DTC cells and tissues was significantly increased compared with normal cells and adjacent normal tissues. DEPTOR protein expression was significantly associated with lymph node status, extrathyroid extension and distant metastasis. Patients exhibiting high DEPTOR expression were statistically susceptible to earlier recurrence and poorer survival than those with low expression. Univariate and multivariate analyses showed that DEPTOR expression was an independent prognostic factor for DTC recurrence. In conclusion, our data indicate DEPTOR as a novel prognostic marker for DTC.
\end{abstract}

Correspondence to: Dr Zhonghua Tang, Department of Breast and Thyroid Surgery, Xiangya Second Hospital, Central South University, Changsha, Hunan 410011, P.R. China

E-mail: tangzhonghua01@hotmail.com

Abbreviations: DEPTOR, DEP domain containing mTORinteracting protein; mTOR, mammalian target of rapamycin; DTC, differentiated thyroid carcinoma; IHC, immunohistochemistry; $\mathrm{ROC}$, receiver operating characteristics; AUC, area under the ROC curve

Key words: DEP domain containing mammalian target of rapamycininteracting protein, differentiated thyroid carcinoma, prognosis

\section{Introduction}

Differentiated thyroid carcinoma (DTC) is the most common histological type of thyroid malignancy and its incidence is increasing (1). Although the majority of DTCs have a relative low mortality, with 10-year survival rates of $83-95 \%$, approximately $30 \%$ of patients with DTC still undergo recurrence during the decades following initial therapy during several decades (2,3). Establishing relevant biomarkers with prognostic significance may prove crucial in reducing the recurrence rate and modifying therapeutic strategies for individual DTC patients (4). To date, few molecular prognostic indicators have been used to evaluate the efficiency of DTC patient diagnosis and prognosis $(5,6)$.

DEP domain containing mammalian target of rapamycin (mTOR)-interacting protein (DEPTOR), a recently identified $48 \mathrm{kDa}$ mTOR-interacting protein, is a novel candidate oncogene (7). DEPTOR is capable of inhibiting mTORC1 signaling and activation of mTORC2 signaling (8-10). As the downstream signal of DEPTOR, mTORC2 protein complex displays PDK-2 activity leading to serine 473 phosphorylation and overactivation of the PI3K/Akt pathway $(11,12)$. Many key functions of PI3K/Akt signaling, such as genetic mutations of kinases and regulatory proteins, epigenetic alterations and post-translational modifications, have already been confirmed by in vitro studies and clinical data in thyroid cancer and a wide variety of other tumors (13-15). The significant role of DEPTOR in regulating tumor growth and progression indicates that it may closely correlate with aggressive clinical behaviors of DTC.

However, the expression level of DEPTOR in DTC is largely unknown and the role of DEPTOR in clinical progression remains to be established. Therefore, we evaluated DEPTOR expression on the mRNA and protein level in thyroid cancer cell lines and tissues to clarify its diagnostic or prognostic value in human DTC.

\section{Materials and methods}

Cell culture. Cell lines were obtained from the Key Laboratory of Cancer Proteomics, Ministry of Health of China and Xiangya 
Cell Biology Institute of Central South University. The normal thyroid follicular epithelial cell line, Nthy-ori 3-1, the papillary cancer cell lines, BCPAP, TPC-1, and the follicular cancer cell line, WRO, were cultured in RPMI-1640 (Gibco/BRL, Gaithersburg, MD, USA) with $2 \mathrm{mM}$ L-glutamine, $10 \%$ fetal bovine serum (FBS) (Gibco), $100 \mathrm{U} / \mathrm{ml}$ penicillin and $100 \mathrm{mg} /$ $\mathrm{ml}$ streptomycin. The follicular cancer cell line, FTC-133, was cultured in DMEM/Ham's F12 medium (Gibco) with $2 \mathrm{mM}$ L-glutamine, $10 \%$ FBS, $100 \mathrm{U} / \mathrm{ml}$ penicillin and $100 \mathrm{mg} / \mathrm{ml}$ streptomycin. All cells were grown in a humidified incubator with $5 \% \mathrm{CO}_{2}$ at $37^{\circ} \mathrm{C}$.

Patients (real-time PCR and Western blot analysis). In total, 30 matched paired thyroid cancer tissues and normal surrounding thyroid tissues (distant areas away from primary DTC) were derived from 30 patients $(8$ male, 22 female; mean age 48 years, range from 21 to 65 years; 24 papillary carcinoma, 6 follicular/follicular variant of papillary carcinomas) in the Second Xiangya Hospital from April 2008 to October 2010. A total of 7 extrathyroid invasive and 6 distant metastastic tissues were obtained collectively from 7 of the 30 DTC patients. All the tissue samples were stored at $-80^{\circ} \mathrm{C}$ until extraction of total mRNA and protein.

Real-time PCR. Total RNA was extracted from cell lines and tissues with the TRIzol RNA extraction kit (Gibco). For cDNA synthesis, total RNA $(2 \mu \mathrm{g})$ was reverse transcribed with the reverse transcriptionase polymerase chain reaction (RT-PCR) high plus kit (Toyobo Co., Ltd., Osaka, Japan). All quantitative PCRs were carried out using the ABI PRISM 7500 Sequence Detector Thermocycler (Applied Biosystems, Carlsbad, CA, USA) and SYBR ${ }^{\circledR}$ Premix Ex $\mathrm{Taq}^{\mathrm{TM}}$ (perfect real time) (Takara Shuzo, Shiga, Japan), PCR was performed in $20 \mu 1$ total volume for each sample, containing $0.4 \mu \mathrm{l}$ forward primer, $0.4 \mu 1$ reverse primer, $10 \mu 1$ SYBR Premix Ex Taq, $0.4 \mu 1$ ROX reference dye, $2 \mu \mathrm{l}$ cDNA and $6.8 \mu \mathrm{l} \mathrm{dH}_{2} \mathrm{O}$. The PCR conditions were as follows: initial denaturation at $95^{\circ} \mathrm{C}$ for $10 \mathrm{sec}$, followed by 40 cycles of denaturation at $95^{\circ} \mathrm{C}$ for $5 \mathrm{sec}$ and annealing/ extension at $60^{\circ} \mathrm{C}$ for $30 \mathrm{sec}$. Human housekeeping gene primer set (Takara, Ohtsu, Japan) was used to select stably expressed reference genes. Gene expressions for DEPTOR were normalised to geometric mean of the expression of the 3 housekeeping genes, ACTB ( $\beta$-actin), RPS18 (ribosomal protein S18) and GAPDH (glyceraldehyde-3-phosphate dehydrogenase) (16-18). The DEPTOR primers used were as follows: forward, 5'-TTTGTGGTGCGAGGAAGTAA-3' and reverse, 5'-CATTGCTTTGTGTCATTCTGG-3' (7).

Western blot analysis. Whole protein from tissues and cell lines was prepared in RIPA buffer containing $50 \mathrm{mM}$ Tris-HCl, pH 7.3, $150 \mathrm{mM} \mathrm{NaCl}, 2 \%$ NP-40, 0.5\% deoxycholate, $2 \mathrm{mM}$ EDTA, $2 \mathrm{mM} \mathrm{NaF}$, and $1 \%$ Protease Inhibitor Cocktail (Pierce, Rockford, USA). Protein concentration was assessed by the Bradford assay (Bio-Rad, Hercules, CA, USA). Total protein $(100 \mu \mathrm{g})$ was separated by $10 \%$ SDS-PAGE and transferred to polyvinylidene difluoride filters (Millipore, MA, USA). Membranes were blocked in $5 \mathrm{mg} / \mathrm{ml}$ non-fat milk and incubated with monoclonal antibodies as follows: mouse anti-human DEPTOR monoclonal antibody (1:500, Abnova
Corporation, clone 5B3, Taipei City, China) or GAPDH (1:500, Sigma-Aldrich, St. Louis, MO, USA). The membranes were then incubated with horseradish-peroxidase-conjugated secondary antibodies (1:2000; KPL, Gaithersburg, MD, USA) and visualized with enhanced chemiluminescence detection reagents (Pierce).

Patients (tissue microarray). A total of 114 consecutive DTC patients who had received thyroidectomy in Second Xiangya Hospital and Hunan Cancer Hospital from May 1996 to October 2010 were enrolled, and /the specimens were assessed with tissue microarray analysis. The tissue blocks included 67 normal surrounding thyroid tissues (distant areas away from DTC), 114 DTC tissues (84 papillary, 30 follicular/follicular variant of papillary carcinomas), 12 extrathyroid invasive and 7 metastastic tissues. The patients were followed-up at 3-month intervals, for a minimum period of 15 months and a maximum period of 14 years. All available clinicopathological data and follow-up data were recorded.

Tissue microarray. The specimens were fixed in $10 \%$ formalin and embedded in paraffin blocks. Triplicate tissue cores with $0.6 \mathrm{mM}$ diameter were punched out of each sample and transferred to a recipient block by using MTA-II tissue microarray instrument (Beecher Instruments, Sun Prairie, WI, USA). Typical lesions corresponding to DTC tumor, normal surrounding, invasive tumor and metastatic tissues were selected according to hematoxylin and eosin staining.

Immunohistochemical staining (IHC). Consecutive 4- $\mu \mathrm{m}$ sections were cut from the TMA paraffin blocks. Slides were boiled in $0.01 \mathrm{M}$ citrate buffer ( $\mathrm{pH}$ 6.0) for antigen retrieval. After blocking with peroxide and 5\% BSA, the slides were incubated with mouse anti-human DEPTOR monoclonal antibody (1:500, Abnova, Taipei City, China) and visualized with the EnVision ${ }^{\text {Tut }}$ FLEX System (Dako, Glostrup, Denmark).

IHC scoring and evaluation. To account for staining percentage and intensity of DEPTOR, $\mathrm{H}$-score was used for DEPTOR immunohistochemistry scoring $(19,20)$. The DEPTOR staining intensity was scored as: $3+$ (strong staining), 2+ (moderate staining), $1+$ (weak staining), or 0 (no staining) and weighted by the corresponding percentage. A score range from $0-300$ was obtained using the formula: $\mathrm{H}$-score $=3 \times$ percentage of strong staining $+2 \mathrm{x}$ percentage of moderate staining + $1 \mathrm{x}$ percentage of weak staining.

To divide samples into DEPTOR-positive and -negative groups, the cut-off scores for DEPTOR expression were selected based on receiver operating characteristic (ROC) curve analysis. The DEPTOR H-score for maximum sensitivity and specificity was selected as the cut-off score leading to the greatest number of correctly classified tumors with or without the clinical outcome (21).

Statistical analysis. All continuous data were presented as the means \pm SD. Continuous variables were tested by the Student's t-test. Categories were compared with the $\chi^{2}$ test or Fisher's exact test. Measurement data of two independent samples were compared by the Wilcoxon signed-rank test. Univariate survival analysis was estimated by the Kaplan- 
A

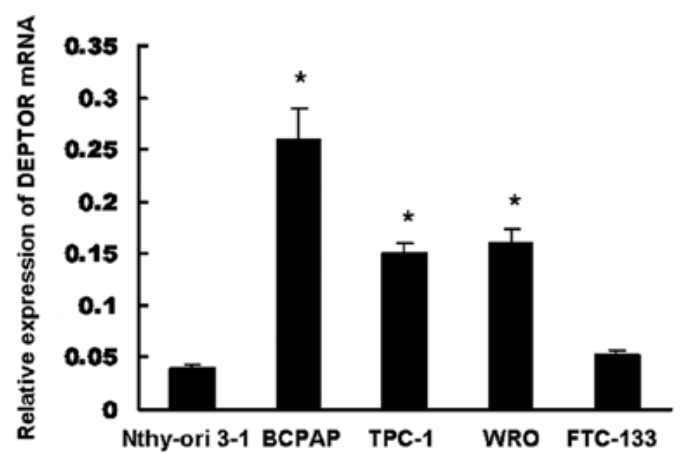

B
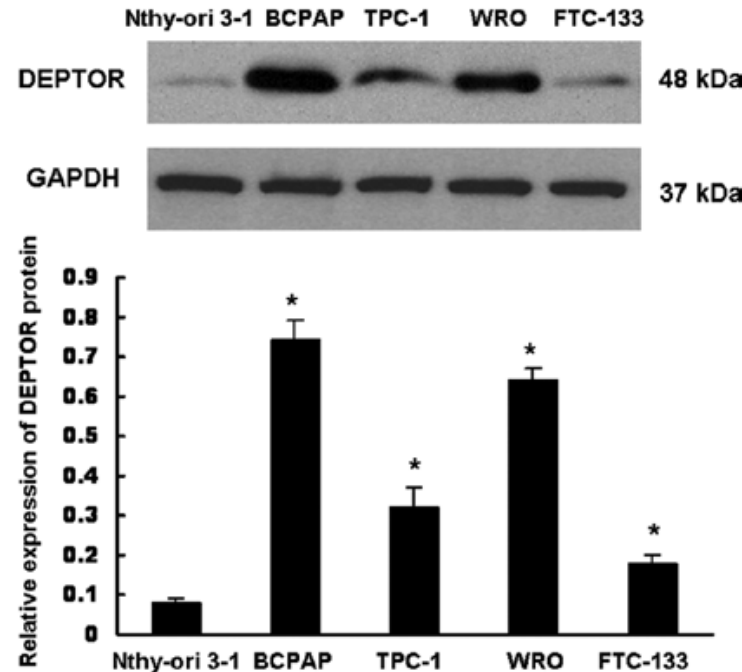

Figure 1. Expression of DEPTOR in cell lines. (A) Relative DEPTOR mRNA levels to the geometric mean of the three reference genes in the normal thyroid cell line, Nthy-ori 3-1, the papillary cancer cell lines, BCPAP and TPC-1, and the follicular cancer cell lines, WRO and FTC-133, by real-time PCR analysis (B) Western blot analysis of DEPTOR protein levels in four DTC thyroid cancer cell lines and normal thyroid epithelial cells were compared. PCR and Western blot analysis experiments were all performed in triplicate. ${ }^{*} \mathrm{P}<0.05$.
$\mathbf{A}$
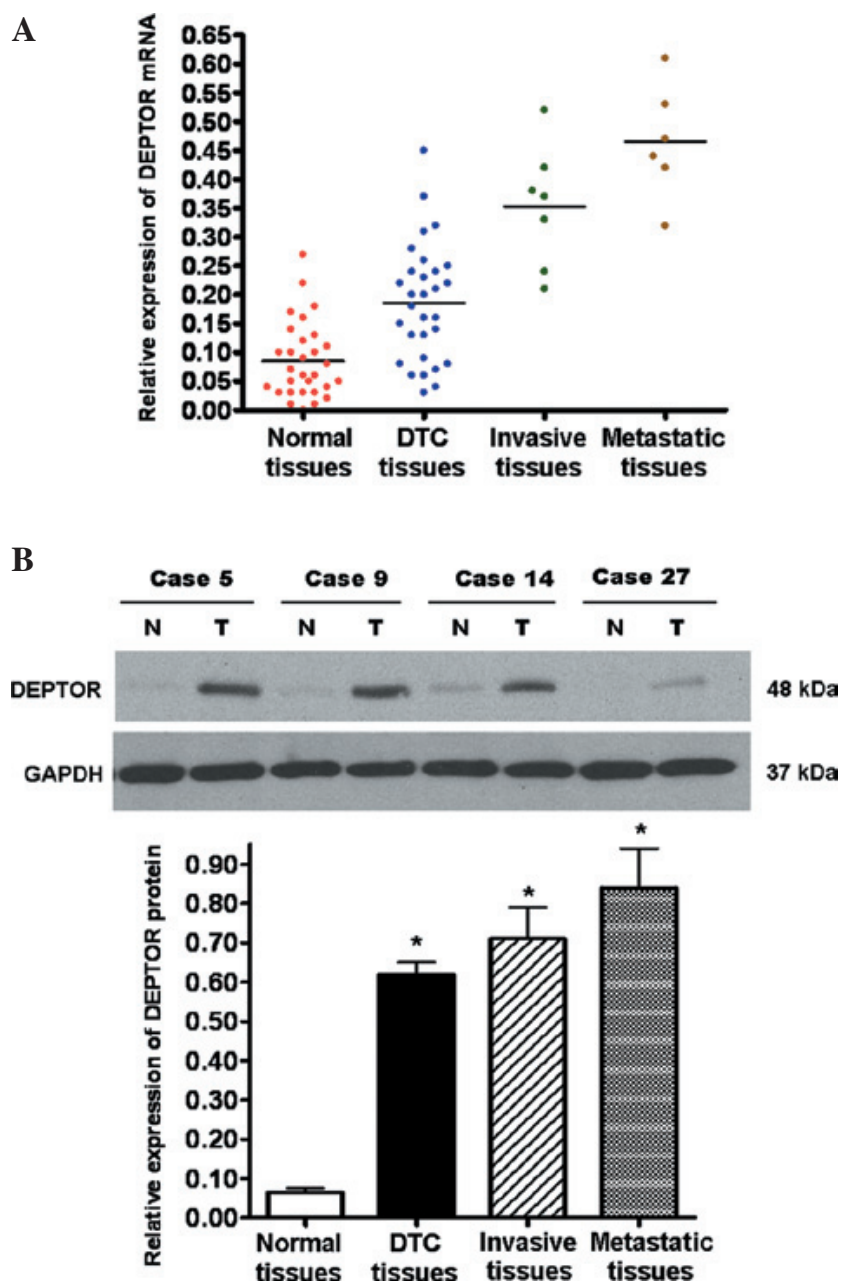

Figure 2. Expression of DEPTOR in DTC tissue samples. (A) DEPTOR mRNA levels relative to the geometric mean of the three reference genes among 30 matched pairs of DTC and corresponding normal tissues, 7 extrathyroid invasion and 6 metastasis tissues. (B) Western blot analysis of DEPTOR protein level in stepwise metastatic-capability DTC tissues. ${ }^{*} \mathrm{P}<0.05$.
Meier method and disease-free survival was compared by the log-rank test. Multivariate analysis by the Cox proportional hazard regression model was used to identify independent prognostic factors in predicting overall cumulative survival. All statistical analyses were performed using statistical software (SPSS 17.0 for Windows, SPSS, Inc., Chicago, IL, USA). A value of $\mathrm{P}<0.05$ was considered statistically significant.

\section{Results}

Expression of DEPTOR in thyroid cancer cell lines. We first determined the DEPTOR expression of the normal thyroid follicular epithelial cell line, Nthy-ori 3-1, the papillary cancer cell lines, BCPAP and TPC-1, and the follicular cancer cell lines, WRO and FTC-133, by real-time PCR and Western blot analysis. We observed that the DEPTOR mRNA level was significantly higher in the thyroid cancer cell lines, BCPAP, TPC-1 and WRO, than in the normal thyroid cell line, Nthy-ori 3-1 (all $\mathrm{P}<0.05$ ), but no marked difference was observed between FTC-133 and Nthy-ori 3-1 ( $\mathrm{P}=0.067$; Fig. 1A). Western blot analysis results revealed that DEPTOR protein was overexpressed in the four DTC cell lines, compared to the thyroid follicular epithelial cell line, Nthy-ori 3-1. BCPAP cells displayed the highest DEPTOR expression among the four DTC cells tested, followed by TPC-1, WRO and FTC-133 (P<0.05; Fig. 1B).

Expression of DEPTOR in thyroid cancer tissues. To examine DEPTOR mRNA expression in DTC tissues, 30 matched pairs of DTC tissues and the corresponding normal thyroid tissues were evealuated using real-time PCR. The results revealed that the expression level of DEPTOR mRNA in DTC tissues was significantly higher compared to normal tissues, $(0.20 \pm 0.09$ vs. $0.08 \pm 0.03$, P=0.013, Fig. 2A). Similarly, DTC tissues exhibited higher protein levels of DEPTOR protein than normal tissues $(0.62 \pm 0.05$ vs. $0.06 \pm 0.01, \mathrm{P}<0.001$; Fig. $2 \mathrm{~B})$. DEPTOR mRNA levels were observed to be positively correlated with protein levels by Pearson's analysis $(\mathrm{r}=0.682, \mathrm{P}=0.035)$. The corresponding 7 extrathyroid invasive and 6 distant metastastic tissues exhibited higher DEPTOR levels than the primary DTC tissues (all $\mathrm{P}<0.05$ ).

DEPTOR exhibited cytoplasmic staining located in the two subtypes of DTC. The distribution of the DEPTOR staining intensity was compared by the Wilcoxon signed rank 
A

C
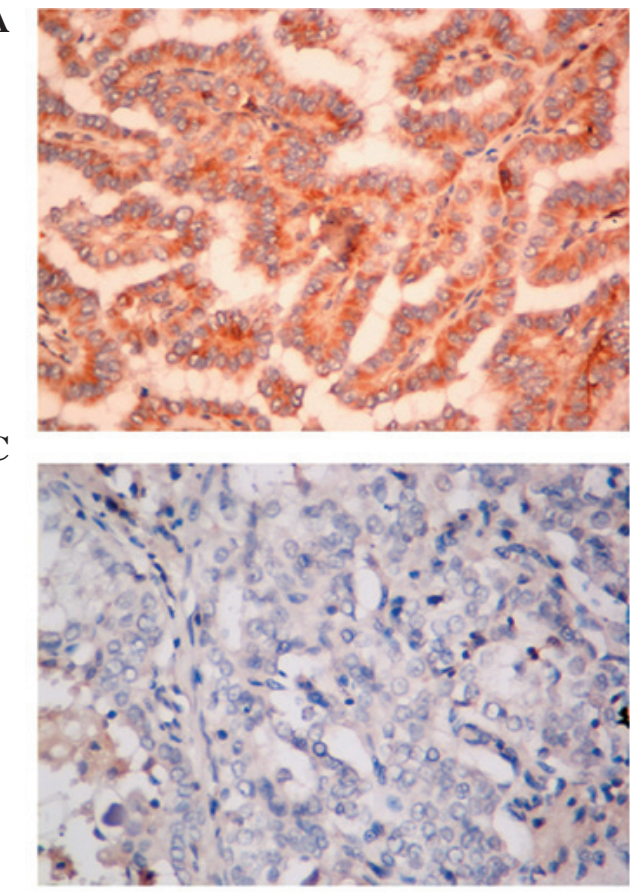

$\mathbf{E}$

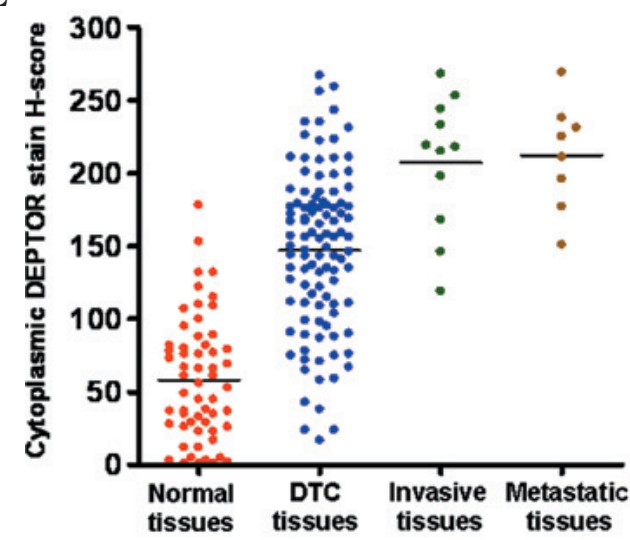

B

D
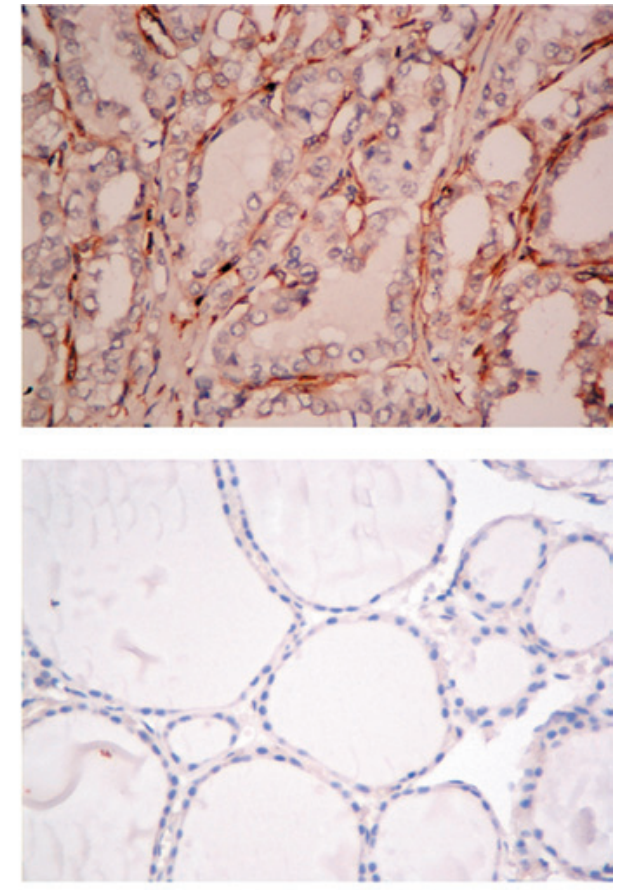

$\mathbf{F}$

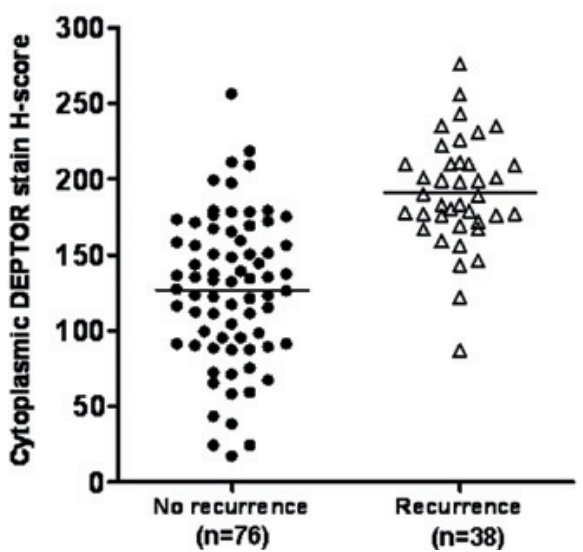

Figure 3. Representative DEPTOR IHC images and staining H-score in DTC and normal thyroid tissues. (A) Strong cytoplasmic DEPTOR staining in DTC (scored as 3+). (B) Moderate cytoplasmic DEPTOR staining in DTC tissues (scored as 2+). (C) Weak cytoplasmic DEPTOR staining in DTC tissues (scored as 1+). (D) No cytoplasmic DEPTOR staining in normal thyroid tissue (scored as 0). Original magnification, x400. (E) Immunohistochemistry cytoplasmic DEPTOR staining H-score in normal, DTC, extrathyroid invasive and metastatic tissues. (F) Comparison of the immunohistochemical cytoplasmic DEPTOR staining $\mathrm{H}$-scores between recurrent and non-recurrent cases in 114 DTC cases.

Table I. Distribution of DEPTOR staining intensity in normal thyroid and thyroid cancer tissues.

\begin{tabular}{lcccc}
\hline $\begin{array}{l}\text { DEPTOR } \\
\text { staining }\end{array}$ & Normal & DTC & $\begin{array}{c}\text { Invasive } \\
\text { tissues } \\
(\mathrm{n}=67)\end{array}$ & $\begin{array}{c}\text { Metastatic } \\
\text { tissues } \\
(\mathrm{n}=7)\end{array}$ \\
\hline 0 & 13 & 0 & 0 & 0 \\
$1+$ & 22 & 35 & 1 & 1 \\
$2+$ & 29 & 54 & 5 & 1 \\
$3+$ & 3 & 25 & 6 & 5 \\
\hline
\end{tabular}

test. As shown in Table I, strong or moderate cytoplasmic staining intensity of DEPTOR was less frequently observed in normal surrounding thyroid tissues than in the DTC, invasive or metastatic tissues (all $\mathrm{P}<0.05$ ).
The cytoplasmic DEPTOR H-score was gradually increased in the DTC tissues $(147.22 \pm 58.51)$, compared to the extrathyroid invasive $(207.51 \pm 46.03)$ and metastatic tissues $(217.31 \pm 37.05)$, significantly higher than normal surrounding tissues (58.09 \pm 39.49 , all $\mathrm{P}<0.05$, Fig. 3E). No discrepancy was observed between extrathyroid invasive and metastatic tissues $(\mathrm{P}=0.183)$.

Positive DEPTOR expression correlates with clinicopathological characteristics and poor prognosis. To evaluate prognostic value of DEPTOR, we categorized 114 tumor specimens into DEPTOR-positive and -negative groups by a cut-off value. The cut-off score was selected as 71 based on ROC curve analysis and the area under the ROC curve (AUC) of the ROC curves was 0.782 . The $\chi^{2}$ test was performed to confirm correlations between DEPTOR protein expression and clinicopathological characteristics. The results indicated that high DEPTOR expression in DTC correlated with lymph 
Table II. Association between DEPTOR expression and clinicopathological data in differentiated thyroid carcinoma.

\begin{tabular}{|c|c|c|c|c|}
\hline Characteristics & $\begin{array}{c}\text { Total } \\
(n=114)\end{array}$ & $\begin{array}{c}\text { DEPTOR } \\
\text { negative } \\
(\mathrm{n}=27)\end{array}$ & $\begin{array}{c}\text { DEPTOR- } \\
\text { positive } \\
(n=87)\end{array}$ & P-valu \\
\hline \multicolumn{5}{|l|}{ Age (years) } \\
\hline$<40$ & 28 & 8 & 20 & 0.484 \\
\hline$\geq 40$ & 86 & 19 & 67 & \\
\hline \multicolumn{5}{|l|}{ Gender } \\
\hline Male & 32 & 5 & 27 & 0.206 \\
\hline Female & 82 & 22 & 60 & \\
\hline \multicolumn{5}{|l|}{ Tumor size $(\mathrm{cm})$} \\
\hline$<1.0$ & 69 & 14 & 55 & 0.291 \\
\hline$\geq 1.0$ & 45 & 13 & 32 & \\
\hline \multicolumn{5}{|l|}{ Cancer type } \\
\hline Papillary & 84 & 16 & 68 & 0.051 \\
\hline Follicular & 30 & 11 & 19 & \\
\hline \multicolumn{5}{|l|}{ Grade } \\
\hline Well & 79 & 20 & 59 & 0.508 \\
\hline Moderate & 23 & 5 & 18 & \\
\hline Poor & 12 & 2 & 10 & \\
\hline \multicolumn{5}{|c|}{ Lymph node status } \\
\hline Positive & 81 & 10 & 71 & $<0.001$ \\
\hline Negative & 33 & 17 & 16 & \\
\hline \multicolumn{5}{|c|}{ Extrathyroid extension } \\
\hline Yes & 16 & 9 & 7 & 0.002 \\
\hline No & 98 & 18 & 80 & \\
\hline \multicolumn{5}{|c|}{ Distant metastasis } \\
\hline M0 & 89 & 16 & 73 & 0.007 \\
\hline M1 & 25 & 11 & 14 & \\
\hline
\end{tabular}

node status $(\mathrm{P}<0.001)$, extrathyroid extension $(\mathrm{P}=0.002)$ and distant metastasis $(\mathrm{P}=0.007)$. No significant correlations were observed in other variables (Table II).

Of the 114 DTC patients, 38 cases recurred post-operatively, which exhibited a higher cytoplasimic DEPTOR H-score than the other 76 cases with no recurrence $(126.78 \pm 48.80$ vs. $191.02 \pm 36.11, \mathrm{P}=0.012$; Fig. $3 \mathrm{~F}$ ). Furthermore, we noted that patients in the high DEPTOR expression group had poorer prognoses than those in the low DEPTOR expression group. The DEPTOR-positive group exhibited a higher post-operational recurrence/metastasis rate than the DEPTORnegative group (log-rank test, $\mathrm{P}=0.029$; Fig. 4A). Finally, the DEPTOR-negative group had a longer survival than the positive cases (log-rank test, $\mathrm{P}=0.016$; Fig. 4B).

Prognostic value of DEPTOR. Clinical prognostic scoring factors for the prognostic assessment were selected according to the schemes of the European Organisation for Research and Treatment of Cancer (EORTC) and TNM $5^{\text {th }}$ edition, including age, tumor size, grade, lymph node status, extrathyroid extension and metastasis. Of all the clinicopathological characteristics, univariate survival analysis of relapse-free
A

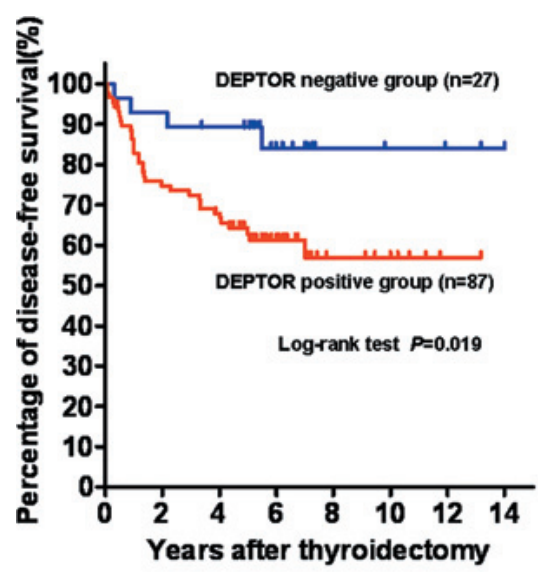

B

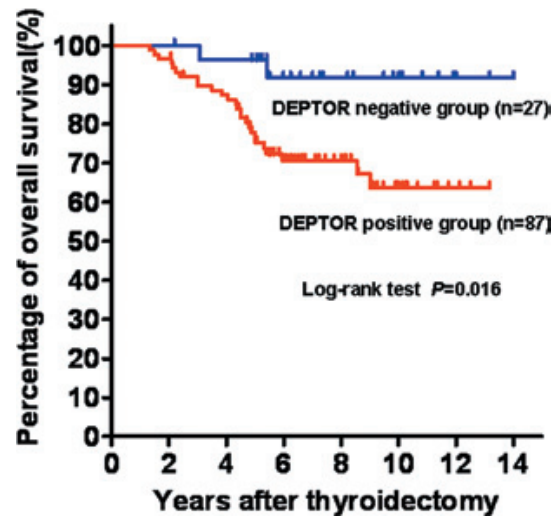

Figure 4. Kaplan-Meier curves of disease-free and overall survival in 114 cases of DTC patients according to the expression of DEPTOR. (A) DTC patients in DEPTOR-positive group have poorer disease-free survival than those in the DEPTOR-negative group (Log-rank test, P=0.029). (B) DTC patients in DEPTOR-positive group also have poorer overall survival than those in the DEPTOR-negative group (Log-rank test, $\mathrm{P}=0.016$ ).

survival demonstrated that DEPTOR expression, age, lymph node status and distant metastasis reached statistical significance (Table III). The Cox multivariate regression analysis confirmed the independent prognostic value of DEPTOR for disease-free survival (HR=1.863; 95\% CI, 1.397-2.491, $\mathrm{P}=0.003$; Table III).

\section{Discussion}

High levels of DEPTOR have been reported in multiple myeloma and paclitaxel-resistant ovarian cancer cell lines $(22,23)$. In view of the potential function of DEPTOR in the development of human cancer, it is necessary to establish the role and clinical significance of DEPTOR. Due to the rare cases of medullary and anaplastic carcinoma, evaluation of DEPTOR expression and clinical value focused only on the DTC histological type in this study. However, the data clearly support the hypothesis that DEPTOR is up-regulated in DTC cell lines and tissues, which is in accordance with previous studies on multiple myeloma. Additionally, an increased expression and frequent presence of DEPTOR expression was observed in parallel with the stepwise metastatic potential of DTC, extrathyroid invasive and metastastic tissues, which constitutes clear evidence of the role of DEPTOR in tumor progression. 
Table III. Univariate and multivariate analyses of recurrence-free survival.

\begin{tabular}{|c|c|c|c|c|c|c|}
\hline \multirow[b]{2}{*}{ Characteristics } & \multicolumn{3}{|c|}{ Univariate analysis } & \multicolumn{3}{|c|}{ Multivariate analysis } \\
\hline & HR & $95 \% \mathrm{CI}$ & $\mathrm{P}$-value & HR & $95 \% \mathrm{CI}$ & $\mathrm{P}$-value \\
\hline \multicolumn{7}{|l|}{ DEPTOR expression } \\
\hline Negative vs. positive & 1.793 & $1.286-2.331$ & 0.001 & 1.863 & $1.397-2.491$ & 0.003 \\
\hline \multicolumn{7}{|l|}{ Age (years) } \\
\hline$<40$ vs. $\geq 40$ & 1.395 & $0.759-2.053$ & 0.005 & 1.425 & $0.922-2.196$ & 0.012 \\
\hline \multicolumn{7}{|l|}{ Tumor size (cm) } \\
\hline$<1.0$ vs. $\geq 1.0$ & 2.279 & $1.608-3.010$ & 0.320 & & & \\
\hline \multicolumn{7}{|l|}{ Grade } \\
\hline Well/moderate vs. poor & 1.632 & $0.775-2.541$ & 0.254 & & & \\
\hline \multicolumn{7}{|l|}{ Lymph node status } \\
\hline No vs. yes & 1.877 & $1.305-2.339$ & 0.011 & 1.991 & $1.452-2.735$ & 0.045 \\
\hline \multicolumn{7}{|l|}{ Extrathyroid extension } \\
\hline No vs. yes & 1.335 & $1.397-2.491$ & 0.058 & & & \\
\hline \multicolumn{7}{|l|}{ Distant metastasis } \\
\hline M0 vs. M1 & 1.448 & $0.870-2.052$ & 0.001 & 1.582 & $0.975-2.561$ & 0.064 \\
\hline
\end{tabular}

Notably, the expression of DEPTOR mRNA in one of the DTC cell lines was not consistent with the high level of protein. Meanwhile, a minority of DTC tissues showed low DEPTOR mRNA levels. We carefully selected a geometric mean of the three housekeeping genes as the relative reference to eliminate the error and confirm the discrepancy. We postulate that a post-translational mechanism may be responsible for the discrepancy between the mRNA and protein levels. In certain DTC cases, DEPTOR protein is cytoplasmically enriched by re-synthesis and reduced degradation, indicating that the ubiquitin-mediated protein system may act as an upstream regulator of DEPTOR (24-26).

By comparison of the cytoplasmic $\mathrm{H}$-scored staining in 114 DTC cases, we observed a significantly higher H-score of DEPTOR in recurrent cases, thus indicating its influence on the recurrence of DTC. Therefore, the advantages of DEPTOR as a tool to predict the long-term survival may be established. This study demonstrates that DEPTOR overexpression was related to lymph node status, extrathyroid extension and distant metastasis. Furthermore, the significance of DEPTOR as a prognostic factor of human DTC has been confirmed. The relapse-free survival analysis data showed a correlation between accumulations of DEPTOR protein and reduced relapse-free survival and overall survival of DTC patients. Although the number of DTC patients analyzed in this study was small, the observation of the clinical correlation of DEPTOR as a novel prognostic indicator of human DTC is significant.

In conclusion, this is the first study to investigate the expression of DEPTOR in human DTC. The initial results provide evidence that DEPTOR is associated with clinical progression behaviors in human DTC. DEPTOR protein expression was significantly and independently associated with shortened relapse-free survival, which suggests its use as a prognostic marker for recurrence and metastasis of DTC.

\section{Acknowledgements}

The authors thank Drs Song Jiang and Liang Zeng for their technical advice.

\section{References}

1. Jemal A, Siegel R, Ward E, Hao Y, Xu J and Thun MJ: Cancer statistics, 2009. CA Cancer J Clin 59: 225-249, 2010.

2. Lee J and Soh EY: Differentiated thyroid carcinoma presenting with distant metastasis at initial diagnosis clinical outcomes and prognostic factors. Ann Surg 251: 114-119, 2010.

3. Vorburger SA, Ubersax L, Schmid SW, Balli M, Candinas D and Seiler CA: Long-term follow-up after complete resection of welldifferentiated cancer confined to the thyroid gland. Ann Surg Oncol 16: 2862-2874, 2009.

4. Yip L, Kebebew E, Milas M, et al: Summary statement: utility of molecular marker testing in thyroid cancer. Surgery 148: 1313-1315, 2010.

5. Papotti M, Rodriguez J, de Pompa R, Bartolazzi A and Rosai J: Galectin-3 and HBME-1 expression in well-differentiated thyroid tumors with follicular architecture of uncertain malignant potential. Mod Pathol 18: 541-546, 2005.

6. Chiu CG, Strugnell SS, Griffith OL, et al: Diagnostic utility of galectin-3 in thyroid cancer. Am J Pathol 176: 2067-2081, 2010.

7. Peterson TR, Laplante M, Thoreen CC, et al: DEPTOR is an mTOR inhibitor frequently overexpressed in multiple myeloma cells and required for their survival. Cell 137: 873-886, 2009.

8. Liu M, Wilk SA, Wang A, et al: Resveratrol inhibits mTOR signaling by promoting the interaction between mTOR and DEPTOR. J Biol Chem 285: 36387-36394, 2010.

9. Wullschleger S, Loewith $\mathrm{R}$ and Hall MN: TOR signaling in growth and metabolism. Cell 124: 471-484, 2006.

10. Guertin DA and Sabatini DM: Defining the role of mTOR in cancer. Cancer Cell 12: 9-22, 2007. 
11. Boyd KD, Walker BA, Wardell CP, Ross FM, Gregory WM, Davies FE and Morgan GJ: High expression levels of the mammalian target of rapamycin inhibitor DEPTOR are predictive of response to thalidomide in myeloma. Leuk Lymphoma 51: 2126-2129, 2010.

12. Sarbassov DD, Guertin DA, Ali SM and Sabatini DM: Phosphorylation and regulation of Akt/pkb by the rictor-mTOR complex. Science 307: 1098-1101, 2005.

13. Zhang S and Yu D: PI (3) king apart PTEN's role in cancer. Clin Cancer Res 16: 4325-4330, 2010.

14. Saji M and Ringel MD: The PI3K-Akt-mTOR pathway in initiation and progression of thyroid tumors. Mol Cell Endocrinol 321: 20-28, 2010.

15. Liu D, Hou P, Liu Z, Wu G and Xing M: Genetic alterations in the phosphoinositide 3-kinase/Akt signaling pathway confer sensitivity of thyroid cancer cells to therapeutic targeting of Akt and mammalian target of rapamycin. Cancer Res 69: 7311-7309, 2009.

16. Yano Y, Uematsu N, Yashiro T, et al: Gene expression profiling identifies platelet-derived growth factor as a diagnostic molecular marker for papillary thyroid carcinoma. Clin Cancer Res 10: 2035-2043, 2004.

17. Bernet VJ, Anderson J, Vaishnav Y, et al: Determination of galectin-3 messenger ribonucleic acid overexpression in papillary thyroid cancer by quantitative reverse transcription-polymerase chain reaction. J Clin Endocrinol Metab 87: 4792-4796, 2002.

18. Cyniak-Magierska A, Wojciechowska-Durczyńska K Krawczyk-Rusiecka K, Zygmunt A and Lewiński A: Thyroid cancer by quantitative reverse transcription-polymerase chain assessment of RET/PTC1 and RET/PTC3 rearrangements in fine-needle aspiration biopsy specimens collected from patients with Hashimoto's thyroiditis. Thyroid Res 4: 5, 2011.
19. Argani P, Hicks J, de Marzo AM, et al: Xp11 translocation renal cell carcinoma (RCC): extended immunohistochemical profile emphasizing novel RCC markers. Am J Surg Pathol 34: 1295-1303, 2010.

20. Stern HM, Padilla M, Wagner K, Amler L and Ashkenazi A: Development of immunohistochemistry assays to assess GALNT14 and FUT3/6 in clinical trials of dulanermin and drozitumab. Clin Cancer Res 16: 1587-1596, 2010.

21. Zhu ZH, Sun BY, Ma Y, et al: Three immunomarker support vector machines-based prognostic classifiers for stage IB nonsmall-cell lung cancer. J Clin Oncol: 27: 1091-1099, 2009.

22. Carrasco DR, Tonon G, Huang Y, et al: High-resolution genomic profiles define distinct clinico-pathogenetic subgroups of multiple myeloma patients. Cancer Cell 9: 313 -325, 2006.

23. Foster H, Coley HM, Goumenou A, Pados G, Harvey A and Karteris E: Differential expression of mTOR signalling components in drug resistance in ovarian cancer. Anticancer Res 30: 3529-3534, 2010.

24. Clague MJ and Urbé S: Ubiquitin: same molecule, different degradation pathway. Cell 143: 682-685, 2010.

25. Qin S, Taglienti M, Nauli SM, Contrino L, Takakura A, Zhou J and Kreidberg JA: Failure to ubiquitinate c-Met leads to hyperactivation of mTOR signaling in a mouse model of autosomal dominant polycystic kidney disease. J Clin Invest 120: 3617-3628, 2010.

26. Maeurer C, Holland S, Pierre S, Potstada W and Scholich K: Sphingosine-1-phosphate induced mTOR-activation is mediated by the E3-ubiquitin ligase PAM. Cell Signal 21: 293-300, 2009. 